\title{
Roles of visual and taste cues in ingestional neophobia: Response latency effects in chicks (Gallus domesticus)
}

\author{
JOSEPH J. FRANCHINA, LERA JOYCE JOHNSON, and P. ANDREW LEYNES \\ Virginia Polytechnic Institute \& State University, Blacksburg, Virginia
}

\begin{abstract}
Latency measures of starting to drink and of consummatory behavior were used to investigate ingestional neophobia to novel visual and novel taste cues in chicks. In Experiment $1(N=36)$, latencies to start drinking were reliably shorter to ingesta that appeared familiar from previous rearing or preexposure procedures. After drinking started, consummatory responding occurred reliably more rapidly to familiar taste cues than to novel ones. However, the presence of familiar visual cues reliably facilitated consumption of a novel taste. Experiments 2 and $3(\mathrm{Ns}=144$ and 180) were performed to evaluate, respectively, whether the ingestional effects of taste stimulus intensity, $0 \%-6 \%$ vinegar, and of visual stimulus intensity, $0 \%-1.0 \%$ concentrations of red foodcoloring in water, changed during ontogeny for chicks 3,5, and 7 days old. In Experiment 2, reliable direct effects of taste concentration on consummatory response latencies occurred immediately in 7-day-olds but were delayed in 3-day-olds. In Experiment 3, each age group immediately showed reliably slower starting and consummatory response times, the higher the concentration of red food-coloring. Intake performance in both experiments was consistent with the latency data. Experiments 1-3 showed that visual and taste cues of ingesta separately influenced approach and consummatory behaviors of the ingestive response sequence and that these influences depend on ontogenetic events.
\end{abstract}

A functional analysis of the stimulus complex occasioned by ingesta suggests that different stimuli influence different aspects of the ingestive sequence. Visual or olfactory cues may provide telereceptive information for elicitation of approach behavior and the start of ingestion; cues from taste or gastric stimulation may provide interoceptive information for consummatory behavior or maintaining ingestion (Brett, Hankins, \& Garcia, 1976; Rusiniak, Hankins, Garcia, \& Brett, 1979). How these stimuli are related and how they influence the ingestive sequence may have implications for understanding initial food acceptance, as in the phenomenon of ingestional neophobia.

Ingestional neophobia refers to the finding that initial presentation of novel food/drink yields minimal intake relative to that after repeated access (see, e.g., Braveman, 1978; Miller \& Holzman, 1981). The unfamiliar appearance of an ingestible may produce neophobia because unfamiliar visual cues may deter approach and, thus, deter the start of ingestion. Consistent with this view is evidence of neophobia to unfamiliar/novel visual cues, found in avian species such as quail and domestic chickens (see, e.g., Franchina \& Slank, 1989; Roper, 1990; Wilcoxon, 1977, p. 444). However, other research with pigeons, quail, and chickens has produced no evidence of neopho-

Correspondence should be addressed to J. J. Franchina, Department of Psychology, Virginia Polytechnic Institute \& State University, Blacksburg, VA 24061-0436. bia to visual cues (e.g., Gillette, Martin, \& Bellingham, 1980 ; Lett, 1980) or evidence that neophobia to visual cues relies on the availability of novel taste cues (e.g., Shettleworth, 1972). Still other studies have shown reliable taste neophobia, irrespective of visual cue novelty (e.g., Franchina \& Slank, 1989; Lett, 1980; Shettleworth, 1972). All considered, the data suggest that the role of visual cues in ingestional neophobia is debatable and/or that the influence of visual cues depends on taste stimulation. The main purpose of the present three experiments was to investigate the separate roles of visual and taste cues in the display of ingestional neophobia.

In most studies of neophobia, the typical measure is intake performance-the amount drunk. Since intake permits a confounding of approach and consummatory behaviors, this measure precludes separate evaluations of the roles of visual and taste cues. However, since visual stimulus control of approach behavior antedates taste stimulus control over consumption, a latency index might permit a separation of effects of vision versus taste. Evidence of neophobia to visual cues would consist in longer latencies to approach an unfamiliar-appearing ingestible than a familiar-appearing one. After the first drink, latencies for continued ingestion of an unfamiliar or unpalatable taste should be longer than those for a familiar taste. The finding that taste cues control consumption with no apparent influence of visual cues would implicate the idea of taste's prepotency over visual cues for ingesta (Lett, 1980; Westbrook, Clarke, \& Provost, 1980). In Experi- 
ment 1 , chicks were measured on latency to ingest a familiar- or novel-appearing solution with a familiar or novel taste (Phase 1). The familiar-appearing solution was clear; the novel one, red colored. The familiar taste was water; the novel one, vinegar. In Phase 2 , all chicks were tested with a colored flavorful solution, red-colored vinegar.

\section{EXPERIMENT 1}

\section{Method}

Subjects. The subjects were 36 experimentally naive White Leghorn chicks from the Center for Poultry Research at Virginia Polytechnic Institute and State University. The chicks were housed in groups of six with ad-lib food and clear water until they were 9-10 days old. Eighteen hours before the start of the experiment, each chick was housed in a hanging wire mesh cage (interior dimensions: $24.4 \times 12.0 \times 12.0 \mathrm{~cm}$ ) with food available but not fluids. The room temperature was $81^{\circ} \mathrm{F}\left( \pm 5^{\circ}\right)$; the room was illuminated by overhead fluorescent lamps from 0700 to $1900 \mathrm{~h}$ daily.

Design and Procedure. Chicks were randomly assigned to Phase 1 preexposure solutions of clear water, red-colored water, clear $4.0 \%$ vinegar, or red-colored $4.0 \%$ vinegar. Preexposures occurred at 0830 and $1630 \mathrm{~h}$ on each of 2 successive days. Phase 2 occurred on the 3 rd day at $0830 \mathrm{~h}$. All chicks received red-colored vinegar.

For preexposure, each chick was placed at the midpoint of the rear wall of a double cage (interior dimensions: $38.1 \times 24.1 \times$ $17.8 \mathrm{~cm})$ approximately $4.5 \mathrm{~cm}$ from a clear glass jar $(6.4 \mathrm{~cm}$ in diameter and $5.8 \mathrm{~cm}$ deep) directly in front. The jar contained 55-60 $\mathrm{cc}$ of the appropriate solution. Release of the chick started a timer and a tape recorder. A drinking response was defined as the chick's dipping its beak into the solution and throwing its head back, its throat palpitating (see Gillette et al., 1980). The experimenter counted softly ("1," " 2 ," " 3 ," etc.) into the tape recorder to record each drink. The sequence of bill dipping and throat palpitation was used to indicate drinking, because once it starts, drinking behavior continues relatively mechanically (Gillette et al., 1980)although on occasion chicks insert and retract their beaks from a container without apparent ingestion. A preexposure trial ended when the chick had completed 10 drinking responses or after $4 \mathrm{~min}$, whichever came first. Latency to the first bill dip was the time elapsed between the experimenter's saying "start" at the release of the chick and " 1 " at the first bill dip. Latency for each of the next 9 bill dips was the time between successive counts. Latency was measured to the nearest .1 sec on a Cronus Single Event Timer. If the chick failed to drink within $60 \mathrm{sec}$ after the start of a preexposure, the experimenter gently inserted the chick's beak into the solution. Such prompted bill dips were repeated up to four times, one every $60 \mathrm{sec}$, if a chick failed to drink freely, and then the preexposure trial was ended. A score of $60 \mathrm{sec}$ was recorded for each prompted bill dip. Prompts were not used in Phase 2. If a chick stopped drinking before completing 10 bill dips within a 4-min period, a score of $60 \mathrm{sec}$ was assigned for each missing drink (Shettleworth, 1972). Thus, latencies in Phase 2 may exceed those in preexposure, because the discontinued chicks did not contribute latencies to the group means in preexposure. To prevent dehydration, all chicks received a 10-min access to clear water in a metal container in the home cage at approximately $1800 \mathrm{~h}$ daily.

The red-colored water was mixed with $1.0 \mathrm{cc}$ of red food-coloring (Kroger Co.) in $100.0 \mathrm{cc}$ of clear tap water. Clear or red vinegar was mixed with $4.0 \mathrm{cc}$ of white distilled vinegar (White House Co.) in $100.0 \mathrm{cc}$ of clear or red-colored water, respectively. On the possibility that the red food-coloring had taste characteristics that influenced drinking, 16 additional chicks were raised with clear water and food ad lib on a diurnal cycle of red light and darkness. The red light was from a $25-\mathrm{W}$ bulb in a portable reflector lamp placed approximately $94.0 \mathrm{~cm}$ in front of the cages and $149.9 \mathrm{~cm}$ above the room floor. A timer controlled lamp onset and offset. Testing occurred under the red light conditions; to minimize the influence of visual cues further, the outsides of the jars were covered with brown-colored paper. Half the chicks received 4-min access to red water; half, to clear water. Mean intakes were $4.3 \mathrm{~g}$ for red water and $4.9 \mathrm{~g}$ for clear water $(F<1)$. These data suggest that taste characteristics of the red food-coloring, if any, did not likely influence intake or latencies for Bill Dips 2-10.

\section{Results}

Figure 1 presents mean latency for Bill Dips 1-10 (BD1-BD10) to each solution on Preexposure Trials 1-4. On Trial 1, latency to start drinking, BD1, was slower to red-colored solutions of water (RW) or vinegar (RV), than to clear solutions, $\mathrm{CW}$ or $\mathrm{CV}$ [visual cues, $F(1,32)=$ $17.98, p<.001]$. No other factors were reliable $(F<$ 1.0). The numbers of birds prompted for BD1 were 9 of 9 in the RV group, 8 in RW, 4 in CW, and 3 in CV. Latencies became shorter over successive bill dips for each solution; but reliably slower drinking still occurred to red than to clear solutions for BD2, BD3, and BD4 [visual cues, $F(1,32)=26.59,15.83$, and 13.87 , respectively, $p \mathrm{~s}<.001]$. No reliable differences occurred for taste cues $(F<1.0)$. For BD5, BD6, and BD7, drinking was reliably slower for vinegar than for water $[F(1,32)=5.00$, 5.61 , and 5.01, respectively, $p \mathrm{~s}<.05$ ].

Unfortunately, the data after BD4 are only suggestive, because $N$ differed; this was especially true for the visual stimulus groups, because some chicks were discontinued for meeting the prompting criterion and their scores did not contribute to the group means.

On Trial 2, latencies to start drinking were again reliably slower to red than to clear solutions [visual cues, $F(1,32)=19.24, p<.001]$. A post hoc comparison also showed that responding was reliably slower to RV than to RW $[t(17)=5.74, p<.01]$. Numbers of birds prompted were 7 in the RV group, 2 in RW, and none in the $\mathrm{CW}$ or $\mathrm{CV}$ groups. No prompts were needed after BD1. To evaluate terminal performance on Trial 2, an analysis of variance (ANOVA) was applied to BD5BD10. No reliable group differences were obtained $(F<$ 1.0). An ANOVA for Trials 3 and 4 revealed no reliable differences anywhere $(p s>.10)$.

Figure 2 presents mean latency for BD1-BD10 to red vinegar. Latencies to start drinking were reliably faster for groups preexposed to red solutions, irrespective of taste characteristics [visual preexposures, $F(1,32)=21.99, p<$ .001 ; taste preexposures, $F<1.0$ ]. After BD1, latencies for the CV-preexposed group declined to the level for RV controls. Latencies for the RW-preexposed group were initially similar to those of RV controls and gradually increased from that level. An ANOVA for all groups on BD1-BD4 yielded a reliable effect of visual preexposure, and reliable interactions of visual preexposure $\times$ bill dip sequence and taste preexposure $\times$ bill dip sequence $[F(1,32,3,96$, and 3,96$)=16.02,3.23$, and $3.53, p s<$ $.001, .05$, and .05]. Comparison of $\mathrm{CV}$ and $\mathrm{RV}$ groups yielded reliable effects for visual preexposure and bill dip sequence, and a reliable preexposure $\times$ sequence inter- 


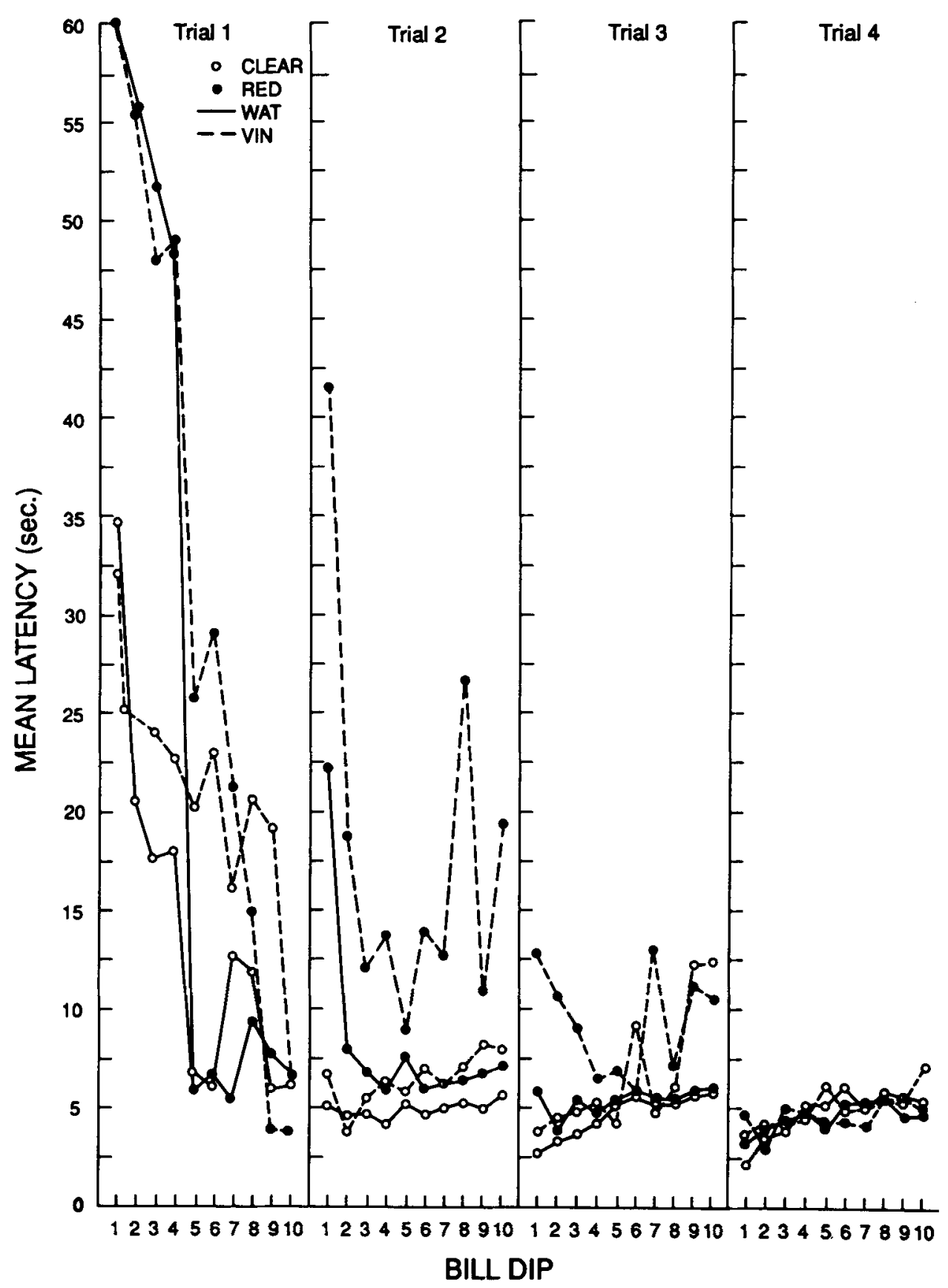

Figure 1. Mean latency for Bill Dips 1-10 to red vinegar, red water, clear vinegar, and clear water on preexposure Trials 1-4.

action $[F(1,16,3,48$, and 3,48$)=9.81,2.96$, and 3.80 , $p \mathrm{~s}<.01, .05$, and .01]. Comparison of RW and RV groups yielded a reliable interaction of taste preexposure $\times$ bill dip sequence $[F(3,48)=4.43, p<.01]$. To evaluate terminal performance, an ANOVA was applied to BD5-BD10. Only taste preexposure was reliable $[F(1,32)=20.79, p<.001]$.

\section{Discussion}

Latency to start drinking on Preexposure Trial 1 and in testing with RV provided reliable evidence for neophobia to visual cues and confirmed the view that the appearance of ingesta provides telereceptive information that affects approach and initial acceptance. Specifically, on Preexposure Trial 1, latency to BD1 was reliably faster 


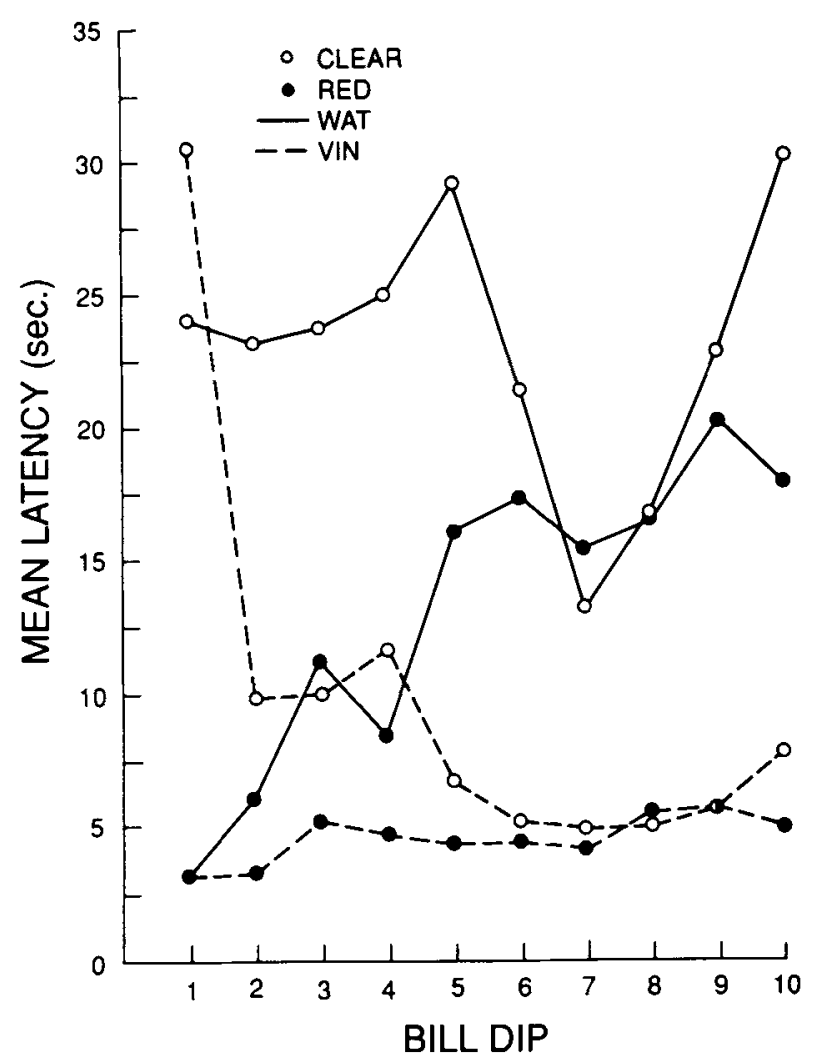

Figure 2. Mean latency for Bill Dips 1-10 in testing with red vinegar following preexposure to clear water, clear vinegar, red water, or red vinegar.

to clear than to red-colored solutions. In testing with RV, latency to BD1 was reliably faster for the RW group, which had been preexposed to a red-colored solution, than for the CW-and CV-preexposed groups. All chicks had been reared preexperimentally with clear water. Presentation of red-colored solutions on Preexposure Trial 1 provided novel visual stimulation that deterred the start of ingestion, presumably because of the aversiveness of novelty (Braveman \& Jarvis, 1978). In testing with RV, the RW-preexposed group initially performed similarly to the RV controls because of RW's prior familiarization with the appearance of the solution. The $\mathrm{CV}$ and $\mathrm{CW}$ groups were reliably slower than the RV controls, presumably because of the novelty of the solution's appearance for them.

It seems plausible to expect that after drinking starts continued ingestion would come under the control of the purportedly more prepotent cues of taste (e.g., Westbrook et al., 1980) and the influence of visual cues on ingestion would become incidental. Lett (1980, p. 198) suggests that a shift in attention occurs from one aspect (visual) of ingesta to another (taste). Results for the CVpreexposed group in RV testing supported this idea. After BD1 provided contact with the familiarized taste of vinegar, the CV group immediately performed similarly to RV controls, despite the presence of novel visual cues.
Results for the RW-exposed group, however, suggest that the presence of familiar visual cues forestalled the deterring effect of novel taste cues on intake. Perhaps familiar visual cues maintained previously established approach behavior, which increased the likelihood of consumption on early bill dips. Consistent with this analysis, on Preexposure Trial 1 the data for BD2, BD3, and BD4 showed no reliable differences between the $\mathrm{CV}$ group, drinking clear vinegar, and the $\mathrm{CW}$ group, drinking clear water. Here the appearance of a clear solution, familiarized in prior rearing, may have kept the chick in the vicinity of the solution, thereby promoting ingestion of a novel taste, vinegar.

\section{EXPERIMENTS 2 and 3}

Experiments 2 and 3 investigated the effects of parametric manipulations of taste or visual cues on neophobia and how the influence of these stimuli might depend on ontogenetic events. If vision and taste serve a functional role in regulating approach and consummatory responses, it seems reasonable to expect that varying the cues along some parameter-say, stimulus intensity-would yield systematic changes in behavior. Thus, in Experiment 2 visual cues of ingesta were held constant and solutions of $0 \%$ (water), $2.0 \%, 4.0 \%$, or $6.0 \%$ concentrations of clear vinegar were presented, in order to study their effects on latencies to start and continue drinking. On the basis of the results of Experiment 1, differences in vinegar concentrations should not influence the start of drinking because the same visual cues would appear for all concentrations. However, after BD1, increasing vinegar concentrations should yield progressively slower consummatory responding.

In Experiment 3, taste cues were held constant and $0 \%, .125 \%, .25 \%$, or $1.0 \%$ concentrations of red foodcoloring in tap water were presented. On the basis of the results of Experiment 1, differences in concentration of red food-coloring should yield differences in visual stimulation, which should influence the start of drinking. A possible hypothesis would be that the higher the concentration, the slower the start. Further, if contact with the familiar taste of water on BD1 results in taste cues' overriding the influence of visual cues, latencies for consummatory responding should not differ across concentrations of red food-coloring.

Studies with rats by Hinderliter and Misanin (1988), Spear and Molina (1987), and Rusiniak, Garcia, Palmerino, and Cabral (1983) indicated that the cues of ingesta that influence neophobia and aversion conditioning change during ontogeny. In avians, a well-developed visual system and a relatively underdeveloped taste receptor system (Clarke, Westbrook, \& Irwin, 1979; Martin \& Bellingham, 1979) may predispose ontogenetic differences in the utilization of visual and taste cues for approach and consumption. For example, manipulation of visual cues may yield differences in approach behavior earlier in ontogeny than manipulation of taste cues in- 
fluences consummatory behavior. Further, because of the visual precocity of birds, no ontogenetic differences may appear in the utilization of visual cues; young birds may be as proficient as older birds. Conversely, for the less well-developed taste receptor system, ontogenetic events may regulate the effects of taste cues.

\section{Method}

Eggs were from the same source as in Experiment 1. After hatching, the chicks were housed in groups of 6 , with yellow-colored water and food available ad lib. Yellow water replaced clear water in rearing (Experiment 1 ), to preclude the possibility that the familiar appearance of a clear solution in testing would diminish the effect of manipulating the taste cues of clear vinegar in Experiment 2 .

At $18 \mathrm{~h}$ before each experiment, the chicks were housed singly with food but without fluids. Within each age group, the chicks were randomly assigned to the solutions for testing. The testing procedures and latency measures were identical to those of Experiment 1 . Each trial lasted $4 \mathrm{~min}$. However, consummatory response latency was the total time to complete nine bill dips after BD1. No prompting procedures were used in Experiments 2 and 3, so that latencies could be much longer than in the preexposure phase of Experiment 1. Total amount drunk on a trial was measured by the difference in the weight of the drinking jars from pre- to posttest. Spillage, which was minimal, occurred infrequently and randomly across solutions.

For Experiment 2, independent groups of chicks 3, 5, or 7 days of age $(N=48 /$ age $)$, received a test trial at 0830 and at $1730 \mathrm{~h}$ on one day and at $0830 \mathrm{~h}$ on the next day. The test solutions were $2.0 \%, 4.0 \%$, or $6.0 \%$ clear vinegar, or water with $0 \%$ vinegar.

Experiment 3 followed the procedures of Experiment 2 with two changes: (1) After rearing with yellow-colored water, all chicks received $8 \mathrm{~h}$ of access to clear water in the group cage, starting $26 \mathrm{~h}$ before the first test trial; (2) there were only two test trialsnamely, on the day when chicks were 3,5 , or 7 days of age $(N=$ $60 /$ age). Test solutions were $0 \%, .125 \%, .25 \%$, or $1.0 \%$ concentrations of red food-coloring in tap water. The vinegar and red water solutions were mixed as in Experiment 1. The yellow-colored water was mixed from $1.0 \mathrm{cc}$ of yellow food-coloring (Kroger Co.) in $200 \mathrm{cc}$ of tap water.

\section{Results}

Experiment 2. Table 1 presents the mean latencies to start drinking for each taste concentration and age group. The ANOVA yielded no reliable effects for taste cues or age $(F \mathrm{~s}<1.0)$.

Figure 3 presents mean latency for Bill Dips 2-10 on Test Trials 1-3. An ANOVA of these data yielded reliable effects of taste and age, and reliable interactions of age $\times$ trials and taste $\times$ age $\times$ trials $\left[F_{\mathrm{s}}(3,132,2,132\right.$, $4,264$, and 12,264$)=11.79,4.05,8.08$, and 2.08 , respectively, $p s<.001, .01, .001$, and .05]. An ANOVA of Trial 1 data revealed that after the first bill dip, taste

Table 1

Mean Latency for the First Bill Dip by 3-, 5-, and 7-Day-Old Chicks to $0 \%$ (Water), $2.0 \%, 4.0 \%$, and $6.0 \%$ Vinegar on Trial 1

\begin{tabular}{crccc}
\hline & \multicolumn{4}{c}{ Concentrations of Vinegar } \\
\cline { 2 - 5 } Age & $0 \%$ & $2.0 \%$ & $4.0 \%$ & $6.0 \%$ \\
\hline 3 & 167 & 162 & 134 & 125 \\
5 & 95 & 122 & 110 & 65 \\
7 & 135 & 100 & 163 & 110 \\
\hline
\end{tabular}

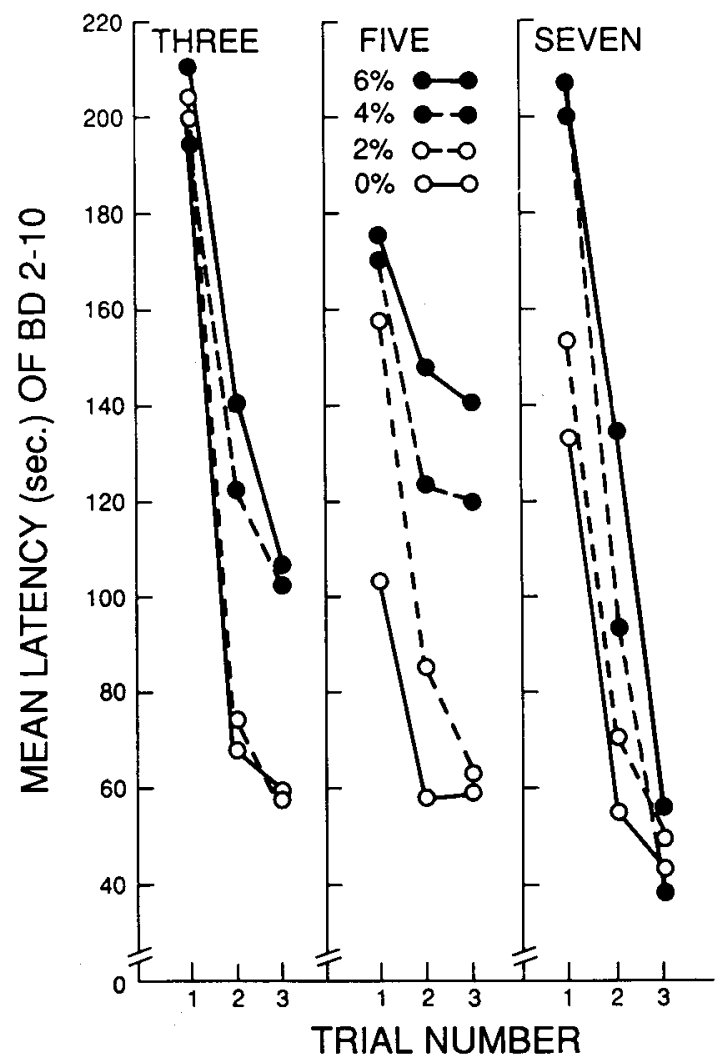

Figure 3. Mean latency for Bill Dips 2-10 for $6.0 \%, 4.0 \%, 2.0 \%$, or $0 \%$ (water) concentrations of vinegar on Trials 1-3 for chicks 3,5 , or 7 days of age.

characteristics reliably produced a direct effect on drinking latencies for older birds but not for the youngest birds. Three-day-olds showed no reliable taste cue effect $(F<$ 1.0). Five-day-olds drank water reliably faster than any vinegar solution $[F(3,44)=3.44, p<.05$; Duncan's multiple range test (DMRT), $p<.05]$. Seven-day-olds drank water and $2.0 \%$ vinegar reliably faster than $4.0 \%$ or $6.0 \%$ vinegar $[F(3,44)=34.87, p<.05$; DMRT, $p<.05]$. Comparisons across ages showed that 5 - and 7-day-olds drank only water and $2.0 \%$ vinegar reliably faster than did 3-day-olds.

Latencies were shorter on Trials 2 and 3 . Vinegar concentrations produced reliable direct effects on drinking for the younger birds while these effects declined for the oldest group. For example, on Trial 3, 3- and 5-day-olds drank water and $2.0 \%$ vinegar reliably faster than they drank $4.0 \%$ or $6.0 \%$ vinegar $[F(3,44)=3.58$ and 4.69 , $p<.05$; DMRT, $p<.05$ ]; 7-day-olds showed no reliable taste effects $(F<1.0)$. Comparisons across ages revealed that 7 -day-olds drank $4.0 \%$ and $6.0 \%$ vinegar reliably faster than did 3- or 5-day-olds (DMRT, $p<.05$ ). No reliable age differences obtained for $2.0 \%$ vinegar or water.

The intake measure (Figure 4) generally corroborated the consummatory latency data. An ANOVA yielded reli- 


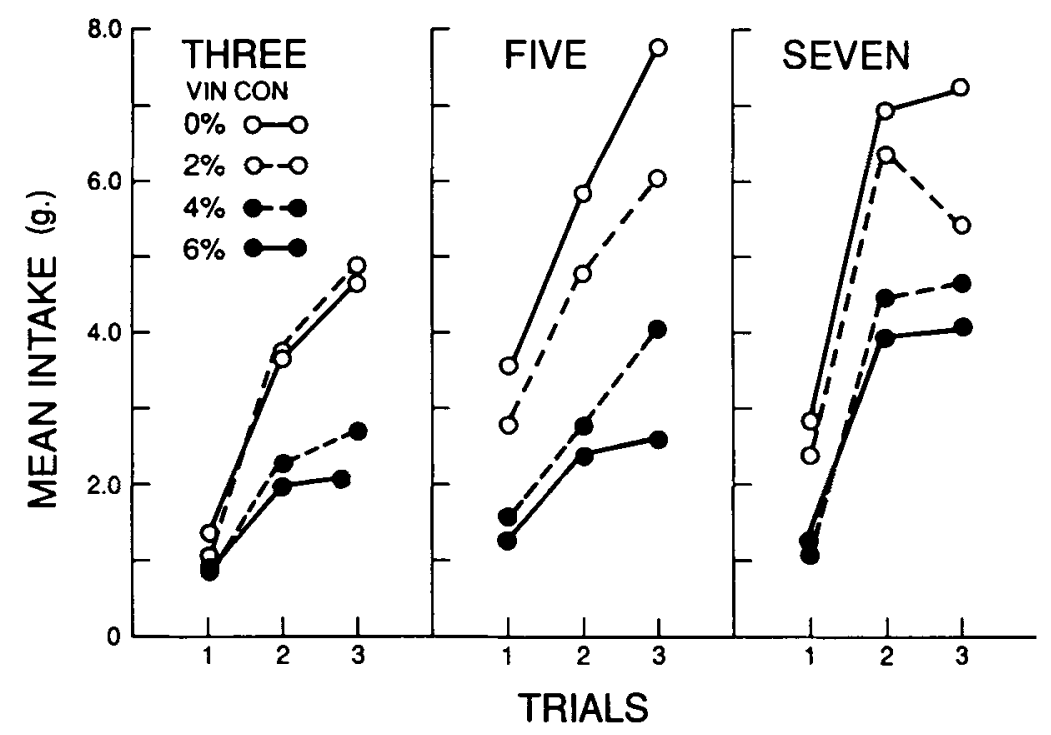

Figure 4. Mean intake of $0 \%$ (water), $2.0 \%, 4.0 \%$, or $6.0 \%$ concentrations of vinegar on Trials 1-3 for chicks 3, 5, or 7 days of age.

able effects of taste and age, and reliable interactions of taste $\times$ trials and age $\times$ trials $[F(3,132,2,132,6,264$, and 4,264$)=35.11,24.46,5.85$, and 9.46 , respectively, $p$ s $<.01]$. Reliable direct effects of taste cues appeared on Trial 1 for 5- and 7-day-olds but not for 3-day-olds $(F<1.0)$. Both older groups drank reliably more water and $2.0 \%$ vinegar than $4.0 \%$ and $6.0 \%$ vinegar $(p<.05)$ and they drank reliably more water and $2.0 \%$ vinegar than did 3-day-olds $(p<.05)$. No age differences were reliable for $4.0 \%$ and $6.0 \%$ vinegar.

By Trial 3, taste characteristics yielded reliable direct effects on intake for all age groups $(p<.05)$. DMRT showed that 3- and 5-day-olds drank reliably more water and $2.0 \%$ vinegar than $4.0 \%$ or $6.0 \%$ vinegar. The 5 -dayolds also drank reliably more water than $2.0 \%$ vinegar $(p<.05)$. Seven-day-olds drank reliably more water than vinegar $(p<.05)$, with no reliable differences in intakes among vinegar solutions. Age-group comparisons showed that both older groups drank reliably more water and $4.0 \%$ vinegar than did the 3-day-olds $(p<.05)$; 7-day-olds drank reliably more $6.0 \%$ vinegar than did 3- and 5-dayolds $(p<.05)$. No reliable age differences were obtained for $2.0 \%$ vinegar.

Experiment 3. Figure 5 shows mean latency to start drinking for each visual cue and age condition on Trials 1 and 2. An ANOVA of these data yielded reliable effects for visual cues and age, and a reliable interaction of visual cues $\times$ trials $\left[F_{\mathrm{S}}(3,168,2,168\right.$, and 3,168$)=18.47$, 14.89 , and $12.57, p<.01]$.

For Trial 1, ANOVA and DMRT reliably showed that drinking started more slowly, the higher the concentration of red food-coloring $[F(3,168)=23.35, p<.001]$ and the younger the bird [age, $F(2,168)=10.72, p<$
$.001]$. Post hoc comparisons showed that a reliable age effect occurred for each red solution $[F \mathrm{~s}(2,42)=3.44$, 4.80 , and $3.33, p<.05$ ], but not for clear water $(F<1.0)$. For Trial 2, an ANOVA and DMRT showed reliable age effects that were similar to those of Trial 1 [age, $F(2,168)=13.03, p<.001$ ]; but the effects of visual cues diminished. Three-day-olds showed reliable differences only between $1.0 \%$ red water and clear water $[F(3,56)=2.89, p<.05]$. Five-day-olds showed reliable differences only between $1.0 \%$ red water and each of the other solutions $[F(3,56)=3.24, p<.05]$. Sevenday-olds showed no reliable differences anywhere $(F<1.0)$.

Figure 6 shows mean latency for Bill Dips 2-10. With minor exceptions, these data repeated those for BD1. An ANOVA yielded reliable effects for age and visual cues and a reliable visual cues $\times$ trials interaction $\left[F_{\mathrm{s}}(2,168\right.$, $3,168$, and 3,168$)=17.19,13.49$, and 5.30, respectively, $p<.001]$. For Trial 1 , the ANOVA revealed reliable age effects for each red solution $[F(2,42)=3.15,4.67$, and 3.50, respectively, $p<.05$ ], but not for clear water $[F(2,42)=2.32, p>.10]$. Three-day-olds drank reliably more slowly than did 7-day-olds, with 5-day-olds in between. On Trial 2 , the only reliable age effect occurred for the $1.0 \%$ solution $[F(2,42)=9.21, p<.001]$. Threeday-olds drank reliably more slowly than did the older birds.

The intake measure (Figure 7) generally corroborated the latency data for consummatory responding. An ANOVA and DMRT over all these data showed that intake increased reliably with age $[F(2,168)=48.96, p<.001]$ and decreased reliably as the concentration of food-coloring increased $[F(3,168)=12.02, p<.001]$. Intake of $1.0 \%$ 


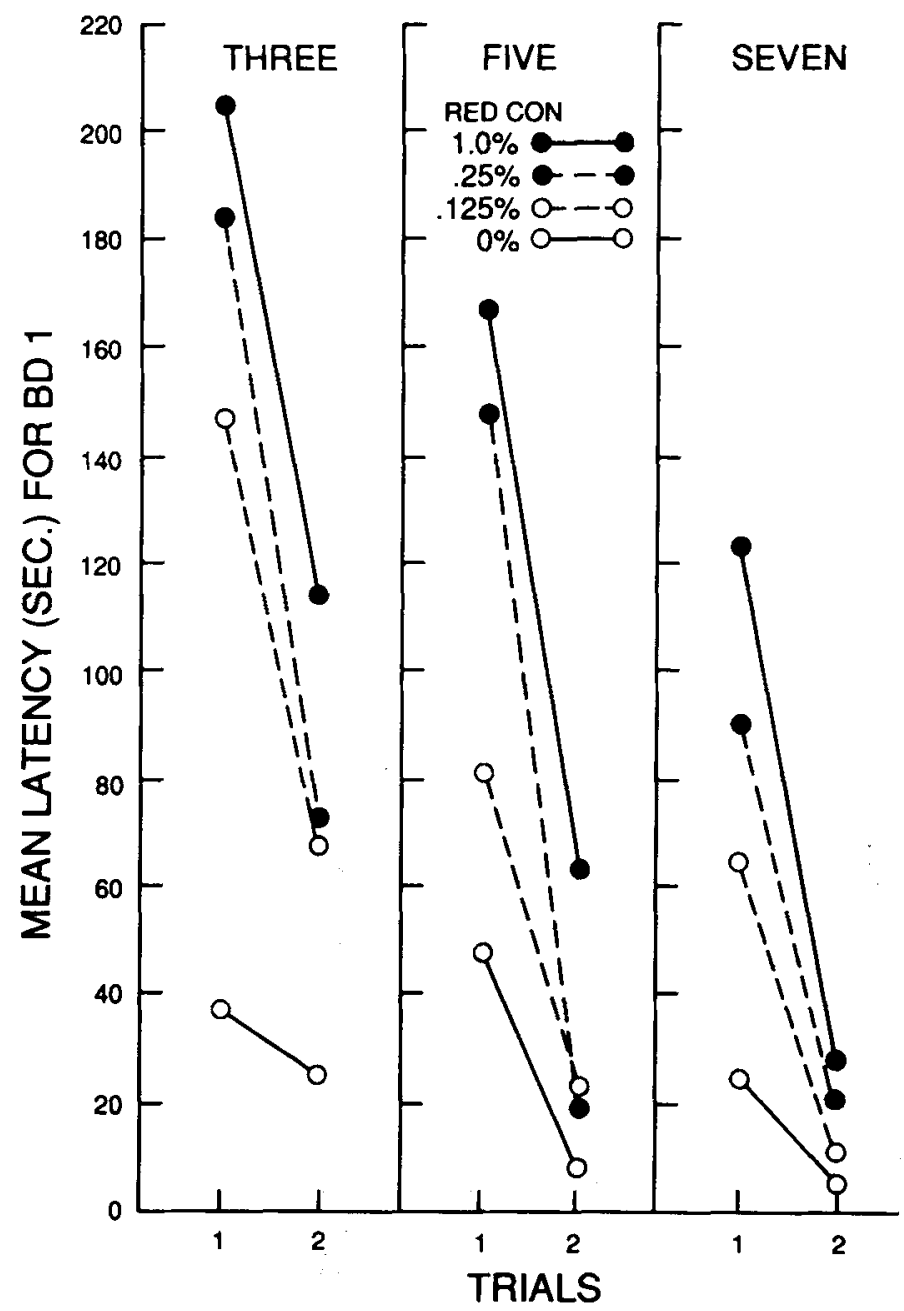

Figure 5. Mean latency for Bill Dip 1 to $1.0 \%, .25 \%, .125 \%$, or $0 \%$ (clear) concentrations of red water on Trials 1 and 2 for chicks 3, 5, or 7 days of age.

red water was reliably less than that for $.25 \%$ or $.125 \%$, which was reliably less than that for clear water $(p s<$ $.05)$. There were no reliable interactions.

\section{Discussion}

Experiment 3 showed that with taste cues held constant, increasing the concentration of red food-coloring reliably and directly delayed the start of drinking on Trial 1 . With visual cues held constant, Experiment 2 showed that latencies to start drinking were similar across taste concentrations on Trial 1. Together, these findings support the hypothesis that visual cues serve a telereceptive function for the start of ingestion.

In Experiment 2, chicks had been reared with yellow water. The appearance of a clear solution for all taste conditions presumably constituted an unfamiliar visual cue and, thereby, deterred ingestion. Evidence that clear solutions appeared novel in Experiment 2 comes from a comparison of mean latencies to start drinking clear water between Experiment 2 (see Table 1: mean latency =
$132 \mathrm{sec}$ ) and Experiment 3 (see Figure 5: mean latency = $32 \mathrm{sec}$ ), averaged across age groups. In Experiment 3, all chicks had had $8 \mathrm{~h}$ of access to clear water prior to Trial 1, making the appearance of a clear solution relatively more familiar than in Experiment 2.

Also, in Experiment 3, the visual cues of clear water in rearing may have served as a referent familiar cue for groups tested with red-colored water. Adding red foodcoloring may have made the appearance of the test solutions increasingly more discrepant from clear water and thus more novel. Unfortunately, increasing the concentration of red food-coloring increased stimulus intensity as well as stimulus novelty. Kalat (1974) reported that for taste cues, the effects of stimulus intensity are separable from those of novelty, with performance effects in favor of the latter. However, Experiment 3 did not include controls that would have permitted this separation-namely, groups preexposed to the highest concentration (1.0\%) of red food-coloring before testing with the lower concentrations. Thus, results of Experiment 3 could reflect novelty or intensity factors. 


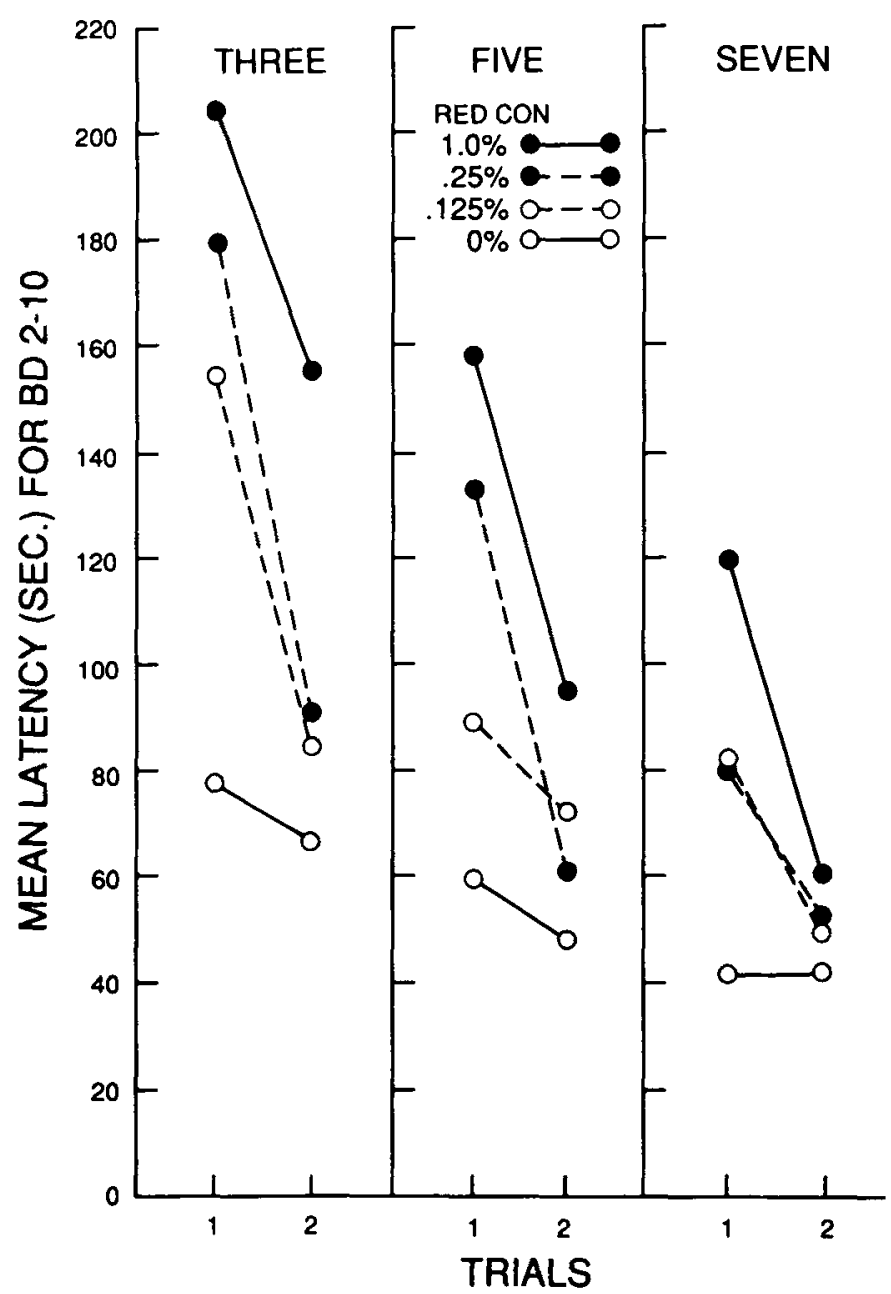

Figure 6. Mean latency for Bill Dips 2-10 to $1.0 \%, .25 \%, .125 \%$, or $0 \%$ (clear) concentrations of red water on Trials 1 and 2 for chicks 3, 5, or 7 days of age.

Intensity of the red color could have influenced the start of drinking because red may be inherently aversive to chicks (Roper, 1990). Roper reported that chicks avoided ingesting mealworms, painted red, irrespective of their prior feeding experience or the background against which the mealworms were presented. Cronhelm (1970) and Kovach (1971), however, reported that red-colored lights or geometric forms evoked pecking and preference behavior in hatchling chicks. Franchina (1991) reported that merely looking at a $1.0 \%$ red-colored solution of water (without ingestion) reliably facilitated subsequent intake of red vinegar. These studies suggest that red coloration may have elicitatory or appetitive properties. If so, finding increasingly slower initiation of drinking as red coloration increased seems an unlikely result of intensity.

The results from BD2-BD10 in Experiment 2 showed that once drinking started, consummatory responding depended directly on taste characteristics of concentrations of vinegar. Visual cues were held constant and should not yield differential responding. However, in Experiment 3, results of BD2-BD10 showed that once drinking familiar water started, consummatory responding depended directly on visual characteristics from concentrations of red food-coloring. Taste cues from familiar water were constant and should not yield differential performance. Both experiments showed that consummatory response latencies were directly related to stimulus concentrations. However, data from Experiment 3 contradicted those of Experiment 2 and the expectations from Lett (1980) and from the data of the CV group in RV testing of Experiment 1 that once a familiar taste (water or vinegar) was detected under the unfamiliar guise of visual cues, that taste would override visual cues and ingestion would be similar across visual conditions. The results of Experiment 3 suggested that the novelty or intensity of red visual cues counteracted the propensity of familiar taste cues to facilitate consumption. Thus, the view that taste cues are necessarily prepotent over visual cues in avians' ingestive behavior (e.g., Clarke et al., 1979; Lett, 1980; Shettleworth, 1972; Westbrook et al., 1980) should be qualified. 


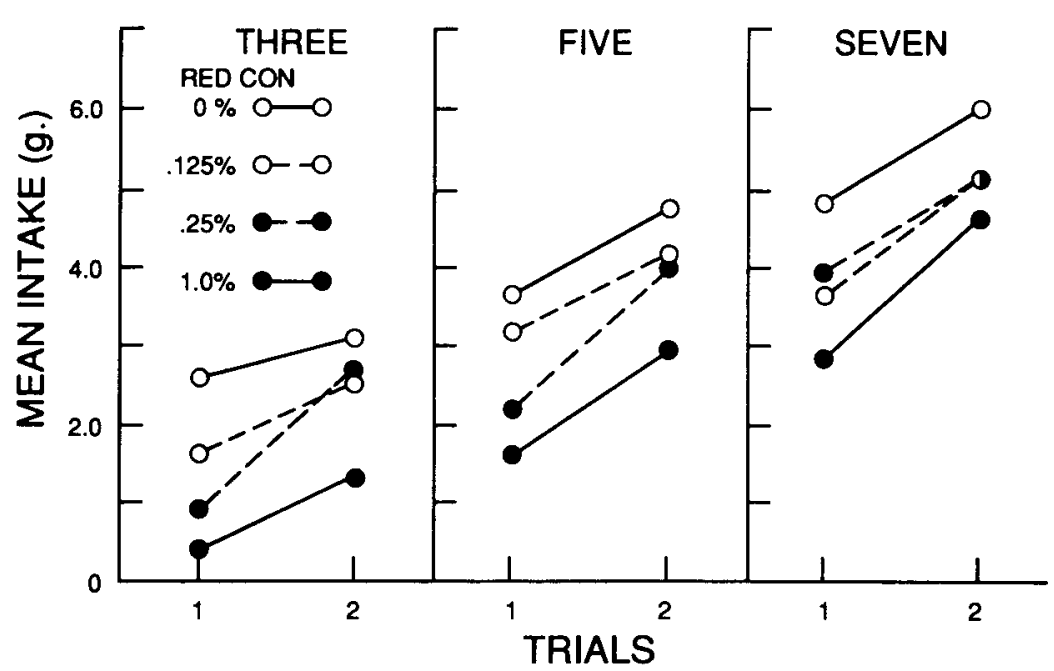

Figure 7. Mean intake of $0 \%$ (clear), .125\%, .25\%, or $1.0 \%$ concentrations of red water on Trials 1 and 2 for chicks 3,5 , or 7 days of age.

One resolution of these contrary results might be that prior experience in the drinking situation mitigated the role of visual stimulus novelty. In Experiment 1, the novel-appearing red solution occurred after four preexposure trials on which the chicks approached and drank clear vinegar; in Experiment 3, the novel-appearing solution occurred at the start of the experiment with no preexposures. Thus, in Experiment 3, a relatively weak approach response may have been more susceptible to the aversive effects of novel visual cues relative to approach in Experiment 1 . There prior experience for the $\mathrm{CV}$-preexposed group may have established approach to contextual cues and response maintenance to vinegar taste cues. Detection of the familiar taste may have evoked associative tendencies that militated against the avoidance tendencies evoked by the novel visual cues.

In Experiment 2, all age groups showed nondifferential effects of visual cues on approach; in Experiment 3, all age groups showed reliable direct effects of increasing concentrations of red food-coloring on approach latency. Finding consistent age effects in each experiment suggests that in precocial birds, such as chicks and quail, the maturity of the visual system at birth predisposes utilization of visual cues in identifying ingestibles at an early age (e.g., Clarke et al., 1979). Hogan (1984) has suggested that avians discriminate edibles from inedibles on the basis of visual factors operative within $72 \mathrm{~h}$ posthatch.

However, in Experiment 3 older birds were reliably faster in approaching red solutions than were the youngest birds. Since age groups showed similar approach latencies to familiar clear water, age differences in approaching red are not likely due to differences in locomotive skills or levels of motivation. Rather, they may indicate that older chicks were less neophobic to visual cues than younger chicks were. Since older birds had a longer, and perhaps more variable, history of using visual cues for the initiation of ingestion, generalization of this function from prior experience may have facilitated approach to novel-appearing ingesta more for them than for younger birds. Other evidence that ontogenetic events produced differences in responding to ingesta cues is the Experiment 2 finding that after drinking started, differential responding on the basis of taste cues occurred earlier, on Trial 1, in older birds than in younger birds. It seems unlikely that these results reflected age-related differences in taste receptor development. Braun-Bartana, Ganchrow, and Steiner (1986) reported that within $24 \mathrm{~h}$ after hatching, chicks are responsive to a variety of taste cues such as those from water, fructose, quinine, and saccharin. Furthermore, on Trial 2 of Experiment 2, the youngest birds showed reliable differences in responding to taste cues. Since Trial 2 followed Trial 1 by approximately $8 \mathrm{~h}$, it seems debatable that sufficient receptor development would have occurred so rapidly to permit differential responding. The earlier occurrence of differential responding in older birds may have reflected their greater exposure to the taste cues of water, received during rearing. This exposure may have permitted 5-day-olds to differentiate responding between water and vinegar solutions on Trial 1, whereas for 7-day-olds, stimulus generalization from the taste characteristics of water to similar cues in vinegar may have facilitated intake of $2.0 \%$ vinegar and water. The relatively limited taste experience for 3-day-olds may have precluded differentiation based on taste until Trial 2.

In summary, the results of Experiments 2 and 3 are consistent with those of Experiment 1 in showing that visual and taste cues influence different aspects of the ingestive response sequence. The influence of these stimuli may depend on events during ontogeny and perhaps on the biological/structural development of the avian. What the interrelationships of visual and taste cues are may have implications for initial food acceptance and for associative phenomena of ingestion. 


\section{REFERENCES}

Braun-Bartana, A., Ganchrow, J. R., \& Steiner, J. E. (1986). Behavioral reactions to taste stimuli in hatchling chicks. In $\mathrm{S}$. D. Roper \& J. Atema (Eds.), Olfaction and taste IX (Annals of the New York Academy of Sciences, Vol. 510, pp. 196-198). New York: New York Academy of Sciences.

Braveman, N. S. (1978). Preexposure to feeding-related stimuli reduces neophobia. Animal Learning \& Behavior, 6, 417-422.

Braveman, N. S., \& JaRVIS, P. S. (1978). Independence of neophobia and taste aversion learning. Animal Learning \& Behavior, 6, 406-412.

Brett, L. P., Hankins, W. G., \& Garcia, J. (1976). Prey-lithium aversions III: Buteo hawks. Behavioral Biology, 17, 87-98.

Clarke, J. C., Westbrook, R. F., \& Irwin, J. (1979). Potentiation instead of overshadowing in the pigeon. Behavioral \& Neural Biology, 25, 18-29.

Cronhelm, E. (1970). Perceptual factors and observational leaming in the behavioural development of young chicks. In J. H. Crook (Ed.), Social behaviour in birds and mammals: Essays on the social ethology of animals and man (pp. 393-439). London: Academic Press.

Franchina, J. J. (1991). Mere exposure to telereceptive cues facilitates intake of a novel flavor in chickens (Gallus domesticus). Behavioral \& Neural Biology, 56, 108-112.

Franchina, J. J., \& SlanK, K. (1989). Role of telereceptive and interoceptive (taste) cues in ingestional neophobia in chicks (Gallus domesticus). Behavioral \& Neural Biology, 52, 116-122.

Gillette, K., Martin, G. M., \& Bellingham, W. P. (1980). Differential use of food and water cues in the formation of conditioned aversions by domestic chicks (Gallus gallus). Journal of Experimental Psychology: Animal Behavior Processes, 6, 99-111.

Hinderliter, C. F., \& Misanin, J. R. (1988). Weanling and senescent rats process simultaneously presented odor and taste differently than young adults. Behavioral \& Neural Biology, 49, 112-117.

Hogan, J. A. (1984). Pecking and feeding in chicks. Learning \& Motivation, 15, 360-376.

KALAT, J. W. (1974). Taste salience depends on novelty, not concentration in taste aversion learning in the rat. Journal of Comparative \& Physiological Psychology, 86, 47-50.
KovaCH, J. K. (1971). Interaction of innate and acquired: Color preferences and early exposure learning in chicks. Journal of Comparative \& Physiological Psychology, 75, 386-396.

LETT, B. T. (1980). Taste potentiates color-sickness associations in pigeons and quail. Animal Learning \& Behavior, 8, 193-198.

Martin, G. M., \& Bellingham, W. P. (1979). Learning of visual food aversions by chickens (Gallus gallus) after long delays. Behavioral \& Neural Biology, 25, 58-68.

Miller, R. R., \& Holzman, A. D. (1981). Neophobias and conditioned taste aversions in rats following exposure to novel flavors. $A n$ imal Learning \& Behavior, 9, 89-100.

ROPER, T. J. (1990). Responses of domestic chicks to artifically-coloured insect prey: Effects of previous experience and background colour. Animal Behaviour, 39, 466-473.

Rusiniak, K. W., Garcia, J., Palmerino, C. C., \& Cabral, R. (1983). Developmental flavor experience affects utilization of odor not taste in toxiphobia conditioning. Behavioral \& Neural Biology, 39, 160-180.

Rusiniak, K. W., Hankins, W. G., Garcia, J., \& Brett, L. P. (1979) Flavor-illness aversions: Potentiation of odor by taste in rats. Behavioral \& Neural Biology, 25, 1-17.

ShETTLEWORTH, S. J. (1972). The role of novelty in learned avoidance of unpalatable "prey" by domestic chicks (Gallus gallus). Animal Behaviour, 20, 29-35.

SPEAR, N. E., \& Molina, J. C. (1987). The role of sensory modality in the ontogeny of stimulus selection. In N. A. Krasnegor, E. M. Blass, M. A. Hofer, \& W. P. Smotherman (Eds.), Perinatal development: A psychobiological perspective (pp. 83-110). Orlando, FL: Academic Press.

Westbrook, R. F., Clarke, J. C., \& Provost, S. (1980). Long-delay learning in the pigeon: Flavor, color and flavor-mediated color aversions. Behavioral \& Neural Biology, 28, 398-407.

WiLcoxon, H. C. (1977). Long-delay learning of ingestive aversions in quail. In L. M. Barker, M. R. Best, \& M. Domjan (Eds.), Learning mechanisms in food selection (pp. 419-453). Waco, TX: Baylor University Press.

(Manuscript received February 13, 1993; revision accepted for publication November 14, 1993.) 